\title{
The relationship between dental health behavior, oral hygiene and gingival status of dental students in the United Arab Emirates
}

Betul Rahman ${ }^{1}$

Sausan Al Kawas²

\section{ABSTRACT}

Objective: The purpose of this study is to assess the impact of knowledge acquired in preventive aspects of dental education on dental students' own health attitudes, oral hygiene and gingival status in the United Arab Emirates.

Methods: To compare the self-reported oral health behavior of first year dental students in the University of Sharjah with their actual oral hygiene and gingival conditions, 93 volunteers who participated in the study completed the Hiroshima University-Dental Behavioral Inventory (HU-DBI) questionnaire. Subsequently a clinical examination for their Plaque Scores (Modified Quigley Hein Plaque Index) and Gingival Bleeding Index was performed by a calibrated dentist.

Results: $29 \%$ of the participants reported bleeding gums; $83 \%$ were concerned by the color of their gums while $63 \%$ reported that it was impossible to prevent gum disease with brushing alone; and only $10 \%$ noticed some sticky white deposits on their teeth. However, approximately $92 \%$ were not in agreement that they would have false teeth when they grew older. $56 \%$ mentioned that they used dental floss regularly and $86 \%$ brushed twice daily or more. Male students had higher bleeding and plaque scores than female students. There appeared to be a significant relationship between plaque scores and HU-DBI responses; in addition to the significant relationship noted between recorded bleeding percentages and HU-DBI responses.

Conclusion: Female students have shown better dental care behavior than male students. The dental students with better self-reported oral health attitudes were expected to have lower plaque scores but instead had moderate plaque and gingival bleeding scores. This indicates the need for more emphasis on preventive measures in oral health education. (Eur J Dent 2013;7:22-27)

Key words: Oral hygiene; gingival status; dental students

1 General and Specialist Dental Practice, College of Dentistry, University of Sharjah, UAE

2 Oral and Craniofacial Health Sciences Department, College of Dentistry, University of Sharjah, UAE

- Corresponding author: Dr. Betul Rahman College of Dentistry, University of Sharjah, P.O.

Box: 27272 Sharjah, UNITED ARAB EMIRATES

Tel: +971504151790

Fax: +971655585641

Email: brahmanđasharjah.ac.ae

\section{INTRODUCTION}

Dentists play an important role in the improvement of the public's oral health education. Therefore, acquiring knowledge and attitudes related to dental health and the prevention of oral diseases is very important during the future dentists' training period. ${ }^{1}$ One of the main objectives of dental education is to train students who can motivate patients to adopt good oral hygiene. They are more 
likely to be able to do this if they themselves are motivated. ${ }^{2}$ Moreover, dental students should be able to apply this knowledge and attitude to their own dental care. ${ }^{3}$

There are controversies among researchers reporting on the impact of education on the attitude, behavior and oral hygiene of dental students. Cortes et $\mathrm{al}^{3}$ in their study found that dental students were highly motivated about maintaining their dental health and their dental education experiences appeared to have had a clear influence on this behavior. Similarly both Lang et al, ${ }^{4}$ Cavaillon et $a l,{ }^{5}$ and Yildiz et $\mathrm{al}^{6}$ noted a clear improvement in the oral hygiene practices of students during their studies. On the other hand, El-Mostehy et $\mathrm{al}^{7}$ in an investigation of 100 Egyptian students noted the absence of an improvement in the practices of oral hygiene in students, in spite of havi-ng received information and education.

In the United Arab Emirates, the oral health system is currently in transition. There is very limited data regarding the knowledge and attitudes about oral diseases and their prevention in the United Arab Emirates. In a previous study we have assessed the dental health knowledge and oral health-related behavior of second year dental and medical students. ${ }^{8}$

The purpose of this study is to assess the impact of preventive aspects of dental education on dental students' own health attitudes, oral hygiene and gingival status in the United Arab Emirates. Based on the findings of this study, changes may be suggested to improve the curriculum, such as, practical sessions to supplement preventive dentistry courses and persistent reinforcement of oral hygiene during the five year dental education period.

\section{MATERIAL AND METHODS}

The study population consisted of a convenience sample of ( $n=93$ ) first year dental students at the University of Sharjah, United Arab Emirates. From a total number of 97 students, 93 of them (response rate $95.8 \%$ ) volunteered to participate in the study.

The Research Ethics Board of the University of Sharjah approved the project. The students were invited to complete the English version of a questionnaire entitled “Hiroshima University-Dental Behavioral Inventory" (HU-DBI) ${ }^{9}$ following a lecture in the second semester of their first year af- ter they had received all the necessary information in preventive dentistry. Dental students as part of their curriculum start learning about preventive aspects of oral health as early as their first year in the college.

Participation in the study was voluntary and the answers were anonymous. Students were given the option of discontinuing at any time.

The HU-DBI questionnaire consisted of twenty polar responses lagree/disagreel regarding oral health-related behavior. In addition, two further questions about the frequency of brushing and flossing were included. (Table 1) A total score was calculated based on the response to each item. Higher scores on the HU-DBI indicated better oral health attitudes/behavior. The possible maximum score was 12 .

To compare the self-reported oral health behavior with the actual clinical situation of participants, a calibrated dentist measured plaque scores (Modified Quigley Hein Plaque Index) and bleeding on probing (Gingival Bleeding Index) of the participants.

To measure the plaque scores after using plaque disclosing agents, plaque was assessed on facial and lingual surfaces of all teeth.

A plaque score was given for each tooth surface from 0 to 5 according to the following criteria: ${ }^{10}$

$0=$ no plaque

1 = separate flecks of plaque at the cervical margin of the tooth

2 = a thin continuous band of plaque lup to 1 $\mathrm{mm}$.) at the cervical margin

$3=$ a band of plaque wider than $1 \mathrm{~mm}$. but cover ing less than one third of the crown

4 = plaque covering at least one third but less than two thirds of the crown

5 = plaque covering two thirds or more of the crown

Plaque score per person was calculated by dividing the sum of all plaque scores of all teeth by the number of tooth surfaces examined.

The presence or absence of gingival bleeding was determined by gentle probing of the gingival crevice with a periodontal probe.

The appearance of bleeding within 10 seconds indicated a positive score that was expressed as a percentage of the total number of gingival margins examined. ${ }^{11}$ For each tooth 1 buccal and 1 lingual/ palatal gingival margins were examined. 
The data was entered into SPSS version 14.0 and used for statistical analysis. The data was analysed for frequency distributions. Chi-square tests were used for gender and group comparisons were made using Nonparametric Mann Whitney tests. The significance level was set at $p \leqslant 0.05$.

\section{RESULTS}

HU-DBI questionnaire items and percentage of agree/disagree responses were presented in Table 1 . Bleeding gums were reported in $29 \%$ of the participants; about $83 \%$ answered that they were concerned by the color of their gums while $63 \%$ reported that it was impossible to prevent gum disease with brushing alone; and only $10 \%$ reported that they had noticed some sticky white deposits on their teeth. However, approximately $92 \%$ were not in agreement that they would have false teeth when they grew older. Related to dental health behavior, about $69 \%$ of the participants reported checking their teeth in the mirror after brushing, $56 \%$ mentioned that they used dental floss regularly while $86 \%$ brushed twice daily or more. In this study, there were statistically significant differences between females and males for item 19 (I use a toothbrush which has hard bristles) and item 21 only (I do use dental floss on a regular basis). $(P<.05)$ However, dental care behavior of female students such as tooth brushing twice daily or more, brushing each of the teeth carefully and usage of dental floss regularly was better than male students.

Table 2 and 3 show the distribution of the subjects by gender and plaque scores/bleeding percentages. Male students had higher bleeding and plaque scores than female students. $(P<.05)$

Table 4 shows the mean HU-DBI scores in relation to plaque/bleeding scores and agreement / disagreement to the HU-DBI items. When plaque scores and bleeding scores were related to the HU-DBI responses, a statistically significant relation was found between seven items $(P<.05)$.

There was a statistically significant relation between agreement with the statement "my gums tend to bleed when I brush my teeth" (item 2) and high plaque and bleeding scores $(P<.05)$. Almost $56 \%$ agreed that they floss every day and there was a significant association with the statement "I do use dental floss on a regular basis" (item 21) and high plaque and bleeding scores $(\mathrm{P}<.05)$.

Table 1. HU-DBI Questionnaire items and percentage of agree / disagree response.

\begin{tabular}{|c|c|c|}
\hline HU-DBI Item Description & Agree $(\%)$ & Disagree $[\%]$ \\
\hline 1. I don't worry much about visiting the dentist & $18,80 \%$ & $81,20 \%$ \\
\hline 2. My gums tend to bleed when I brush my teeth (D) & $28,60 \%$ & $71,40 \%$ \\
\hline 3. I worry about the color of my teeth & $38,10 \%$ & $61,90 \%$ \\
\hline 4. I have noticed some white sticky deposits on my teeth (A) & $10,40 \%$ & $89,60 \%$ \\
\hline 5. I use a child-sized toothbrush & $1,40 \%$ & $98,60 \%$ \\
\hline 6. I think that I cannot help having false teeth when I am old (D) & $8,40 \%$ & $91,60 \%$ \\
\hline 7. I am bothered by the color of my gums & $83,10 \%$ & $16,90 \%$ \\
\hline 8. I think my teeth are getting worse despite my daily brushing (D) & $24,50 \%$ & $75,50 \%$ \\
\hline 9. I brush each of my teeth carefully (A) & $47,60 \%$ & $52,40 \%$ \\
\hline 10. I have never been taught professionally how to brush (D) & $0,90 \%$ & $99,10 \%$ \\
\hline 11. I think I can clean my teeth well without using toothpaste (A) & $1,70 \%$ & $98,30 \%$ \\
\hline 12. I often check my teeth in a mirror after brushing (A) & $69,10 \%$ & $30,90 \%$ \\
\hline 13. I worry about having bad breath & $67,40 \%$ & $32,60 \%$ \\
\hline 14. It is impossible to prevent gum disease with toothbrushing alone $(\mathrm{A})$ & $62,60 \%$ & $37,40 \%$ \\
\hline 15. I put off going to the dentist until I have toothache (D) & $19,80 \%$ & $80,20 \%$ \\
\hline 16. I have used a dye to see how clean my teeth are $(A)$ & $91,1 \%$ & $8,90 \%$ \\
\hline 17. I use a toothbrush with hard bristles & $32 \%$ & $68 \%$ \\
\hline 18. I don't feel I've brushed well unless I brush with strong strokes & $23,40 \%$ & $76,60 \%$ \\
\hline 19. I feel I sometimes take too much time to brush my teeth (A) & $31,50 \%$ & $68,50 \%$ \\
\hline 20. I have had my dentist tell me that I brush very well & $43,70 \%$ & $56,30 \%$ \\
\hline 21. I do use tooth floss on regular basis (A) & $56 \%$ & $44 \%$ \\
\hline 22. I brush my teeth twice daily or more $(A)$ & $86 \%$ & $14 \%$ \\
\hline
\end{tabular}


A relation was also observed between low disagreement with the statement "I brush my teeth twice daily or more" (item 22) and high plaque and bleeding scores $(P<.05)$.

\section{DISCUSSION}

The aim of this research was to study the dental health of dental students during their academic training and to assess the extent to which the knowledge acquired was reflected in their own dental care. In the College of Dentistry, University of Sharjah, students are taught plaque control, tooth brushing techniques and flossing as early as their first year in college.

The rather small cohort in this study resulted in a small subsample of the group studied. Therefore, further research using a larger cohort is warranted. This was also a convenience sample of a

Table 2. Distribution of subjects by gender and the plaque scores observed.

\begin{tabular}{|c|c|c|c|c|c|c|c|c|c|c|c|c|}
\hline \multirow{3}{*}{ Gender } & \multicolumn{12}{|c|}{ Plaque score } \\
\hline & \multicolumn{2}{|c|}{0} & \multicolumn{2}{|c|}{1} & \multicolumn{2}{|c|}{2} & \multicolumn{2}{|c|}{3} & \multicolumn{2}{|c|}{4} & \multicolumn{2}{|c|}{5} \\
\hline & $\mathrm{n}$ & $\%$ & $n$ & $\%$ & $\mathrm{n}$ & $\%$ & $\mathrm{n}$ & $\%$ & $\mathrm{n}$ & $\%$ & $\mathrm{n}$ & $\%$ \\
\hline female $n=79$ & 0 & $0 \%$ & 5 & $6 \%$ & 31 & $39 \%$ & 27 & $34 \%$ & 8 & $10 \%$ & 8 & $10 \%$ \\
\hline male $n=14$ & 0 & $0 \%$ & 0 & $0 \%$ & 2 & $14.2 \%$ & 6 & $43 \%$ & 4 & $28.5 \%$ & 2 & $14.2 \%$ \\
\hline Total $n=93$ & 0 & $0 \%$ & 5 & $5.4 \%$ & 33 & $35.5 \%$ & 33 & $35.5 \%$ & 12 & $12.9 \%$ & 10 & $10.7 \%$ \\
\hline
\end{tabular}

Table 3. Distribution of subjects by gender and the gingival bleeding percentages observed.

\begin{tabular}{|c|c|c|c|c|c|c|c|c|c|c|}
\hline \multirow{3}{*}{ Gender } & \multicolumn{10}{|c|}{ Gingival Bleeding Index } \\
\hline & \multicolumn{2}{|c|}{$0 \%$} & \multicolumn{2}{|c|}{$1 \%-25 \%$} & \multicolumn{2}{|c|}{$26 \%-50 \%$} & \multicolumn{2}{|c|}{$51 \%-75 \%$} & \multicolumn{2}{|c|}{$76 \%-100 \%$} \\
\hline & $\mathrm{n}$ & $\%$ & $\mathrm{n}$ & $\%$ & $\mathrm{n}$ & $\%$ & $\mathrm{n}$ & $\%$ & $\mathrm{n}$ & $\%$ \\
\hline female $n=79$ & 0 & $0 \%$ & 18 & $23 \%$ & 37 & $47 \%$ & 19 & $24 \%$ & 5 & $6 \%$ \\
\hline male $n=14$ & 0 & $0 \%$ & 2 & $12 \%$ & 8 & $56 \%$ & 3 & $23 \%$ & 1 & $9 \%$ \\
\hline Total $n=93$ & 0 & $0 \%$ & 20 & $21.5 \%$ & 45 & $48.4 \%$ & 22 & $23.6 \%$ & 6 & $6.5 \%$ \\
\hline
\end{tabular}

Table 4. Mean HU-DBI scores in relation to plaque/bleeding scores and the agreement/disagreement to the HU-DBI items.

\begin{tabular}{|c|c|c|c|c|c|}
\hline Items & Response & $\begin{array}{l}\text { Plaque score } \\
\qquad(0-2)\end{array}$ & $\begin{array}{c}\text { Plaque score } \\
\qquad(3-5)\end{array}$ & $\begin{array}{l}\text { Gingival bleeding score } \\
(0 \%-25 \%)\end{array}$ & $\begin{array}{l}\text { Gingival bleeding score } \\
(26 \%-80 \%)\end{array}$ \\
\hline Item 1 & agree - disagree & $2.86-2.69$ & $4.70-4.26$ & $3.75-4.68$ & $6.02-7.56$ \\
\hline Item 2 & agree - disagree & $* 4.05-* 2.01$ & *6.85 - *3.84 & $4.69-3.65$ & $* 7.05-* 3.86$ \\
\hline Item 3 & agree - disagree & $2.75-2.63$ & $2.65-2.03$ & $4.35-3.45$ & $4.56-3.68$ \\
\hline Item 4 & agree - disagree & $3.58-2.75$ & $* 7.24-* 3.29$ & $6.41-3.64$ & $* 9.43-* 3.90$ \\
\hline Item 5 & agree - disagree & $2.74-2.62$ & $4.23-3.25$ & $3.54-3.24$ & $2.68-2.53$ \\
\hline Item 6 & agree - disagree & $3.54-2.75$ & $4.32-4.25$ & $3.87-3.23$ & $5.46-4.28$ \\
\hline Item 7 & agree - disagree & $* 4.56-* 2.71$ & $* 5.05-* 2.65$ & $4.53-3.61$ & $* 7.06-* 4.02$ \\
\hline Item 8 & agree - disagree & $2.51-2.71$ & $3.57-2.56$ & $2.73-2.64$ & $5.76-3.84$ \\
\hline Item 9 & agree - disagree & $3.02-2.26$ & $6.42-3.71$ & $4.21-3.81$ & $* 5.74-* 2.83$ \\
\hline Item 10 & agree - disagree & $3.75-2.76$ & $6.78-3.86$ & $4.06-4.11$ & $6.15-6.03$ \\
\hline Item 11 & agree - disagree & $2.86-3.75$ & $2.79-3.12$ & $2.52-3.56$ & $3.89-4.25$ \\
\hline Item 12 & agree - disagree & $6.82-6.51$ & $4.36-4.58$ & $4.13-3.98$ & $6.52-5.45$ \\
\hline Item 13 & agree - disagree & $3.54-2.89$ & $8.03-6.42$ & $6.20-3.81$ & $4.58-3.49$ \\
\hline Item 14 & agree - disagree & $2.65-2.67$ & $7.04-5.87$ & $4.87-4.42$ & $7.16-4.71$ \\
\hline Item 15 & agree - disagree & $7.15-5.47$ & $* 3.89-* 1.51$ & $4.01-2.21$ & *6.71 - *3.24 \\
\hline Item 16 & agree - disagree & $6.52-6.23$ & $3.26-2.86$ & $5.64-4.57$ & $3.08-4.12$ \\
\hline Item 17 & agree - disagree & $2.88-2.35$ & $2.39-2.89$ & $3.92-3.87$ & $2.64-2.87$ \\
\hline Item 18 & agree - disagree & $3.21-2.54$ & $5.16-4.52$ & $3.08-4.05$ & $4.55-6.42$ \\
\hline Item 19 & agree - disagree & $2.05-3.25$ & $3.37-5.21$ & $4.21-3.85$ & $5.63-4.88$ \\
\hline Item 20 & agree - disagree & $3.31-2.23$ & $3.23-2.53$ & $3.92-4.23$ & $3.31-4.25$ \\
\hline Item 21 & agree - disagree & $* 7.22-* 3.36$ & $* 9.65-* 5.21$ & $* 8.25-* 5.31$ & $* 7.45-* 3.21$ \\
\hline Item 22 & agree - disagree & $6.36-5.21$ & $* 6.51-* 3.24$ & $* 2.46-* 4.12$ & $* 9.63-* 3.87$ \\
\hline
\end{tabular}


new batch of first year dental students, a fact that limits the possibility of generalization to other population groups.

Gender was major factors influencing the HUDBI percentage of agree/disagree responses in our study. This finding is in consistence with a previous survey in which dental health knowledge, attitude and behavior among Jordanian dental students was assessed. ${ }^{12}$ Female dental students showed a significantly better attitude than their male colleagues as was reported by Al-Wahadni et $\mathrm{al}^{13}$ and Petersen et al. ${ }^{14}$ This condition may be explained on the basis that females usually are more esthetically conscious. They would be more interested in visiting the dentist and would tend to be better informed about their oral health even before entering a course related to dentistry. ${ }^{15}$ This study is in agreement with the previous studies, ${ }^{13,14,15}$ where female students were found to report better oral health behavior than male students regarding brushing twice daily, brushing each tooth carefully and flossing regularly. Higher plaque and bleeding scores found among the male dental students may reflect this behavior. In contrast to our results, Khami et $\mathrm{al}^{16}$ found no gender difference in the knowledge, attitude and behavior of Iranian dental students.

The majority of the students with higher HU$\mathrm{DBI}$ scores (with better self-reported behavior and awareness) had moderate to high plaque and gingival bleeding scores. This could be an important factor that reflects the oral health attitudes of students entering the dental field. Several studies have reported that dental health attitudes become more positive and are improved as the level of education increases. ${ }^{13,15,17}$ On the contrary, El Mostehy et $a l,{ }^{7}$ reported the absence of an improvement in oral hygiene practices of dental students regardless of having obtained information and education. Our reason to choose first year dental students was to understand the immediate effects of the knowledge they acquired in preventive dentistry in this year and its effects on their oral health attitudes, actual oral hygiene and gingival health. There is an apparent contradiction between acquired knowledge and its practice among dental students. This study reflected a significant relationship between brushing twice daily or more and high plaque and bleeding scores $(P<.05)$. This finding may also represent either an improper way of brushing or no flossing or exaggerated agreement responses. Similarly, Bakdash and Proshek18 in their study noted that many second year dental students did not demonstrate effective oral hygiene habits despite being exposed to an educational course in preventive dentistry in their first year.

It appears that two of the statistically significant relationships between participants' responses on the HU-DBI and plaque and bleeding scores document that participants who had poor oral health might be aware of this fact. There was a relationship, for example, between responses to "My gums tend to bleed when I brush my teeth" (item 2) or "I have noticed some white sticky deposits on my teeth" (item 4) and high plaque and bleeding scores. This indicates poor oral hygiene that leads to gingival signs (bleeding). It appears that these items require participants to be observant of their oral health status as well as plaque and bleeding scores which measure oral health attitude. Items 5 "I use a child-sized toothbrush" and item 9 "I brush each of my teeth carefully" demonstrate the awareness of the importance of careful tooth brushing. The attention to the toothbrush type could indicate a better attitude towards oral health. This attitude might also cause more frequent dental checkups and regular dental treatments, which may result in better dental and gingival health.

This study suggests an association between oral health attitudes, oral hygiene and gingival health among the junior dental students in the United Arab Emirates. Even though students showed a high level of oral health attitude, it was not reflected on their oral hygiene and gingival status. Hence, we recommend modifications in the curriculum of preventive dentistry courses. The inclusion of attractive and effective educational materials such as practical sessions of brushing and flossing techniques along with the use of other interdental cleaning aids, oral irrigation devices and plaque disclosing agents would help achieve optimum plaque control. Likewise, effective oral hygiene must be constantly reinforced during the five year dental education period. It would be motivating and educational to carry on with this study in order to assess the dental care behavior of current junior students until they reach their fifth year in dental education and the impact of their professional knowledge and skills. Further studies on 
dental health behavior and oral hygiene are vital among students in colleges other than the health sciences colleges and among school students since there is very limited data about this issue in the United Arab Emirates.

\section{CONCLUSION}

- Female students have shown better dental care behavior than male students.

- Male students' higher plaque and bleeding scores reflect their lower oral health attitudes.

- The students with better self-reported oral health attitudes were expected to have lower plaque scores but instead had moderate plaque and gingival bleeding scores; this indicates the need for more emphasis on preventive measures in oral health education.

- The relationship between the HU-DBI responses with regard to the awareness of poor oral hygiene and high plaque and bleeding scores points to the need for more motivation in oral hygiene practices among students in dental health education.

\section{ACKNOWLEDGMENTS}

The authors wish to express their appreciation for Dr. Kauser Sadia Fakhruddin for her valuable contribution to this study. We also would like to thank Mrs. Aaliya Sheikh for her help in proofreading the English language.

\section{REFERENCES}

1. Bertolami C. Rationalizing the dental curriculum in light of current disease prevalence and patient demand for treatment: form vs. content. J Dent Educ 2001;65:725-735.

2. Cortes FJ, Nevot C, Ramon JM, Cuenca E. The Evolution of Dental Health in Dental Students at the University of Barcelona. J Dent Educ 2002;66:1203-1208.

3. Yorty JS, Brown B. Caries risk assessment/treatment programs in U.S. dental schools. J Dent Educ 1999;63:745-747.

4. Lang NP, Cumming BR, Loe HA. Oral hygiene and gingival health of Danish dental students and faculty. Community Dent Oral Epidemiol 1977;5:237-242.

5. Cavaillon JP, Conge M, Mirisch D, Nemeth T, Sitbon JM. Longitudinal study on oral health of dental students at Paris VII University. Community Dent Oral Epidemiol 1982;10:137143.

6. Yildiz S, Dogan B. Self reported dental health attitudes and behavior of dental students in Turkey. Eur J Dent 2011;5: 253-259.
7. El-Mostehy MR, Zaki HA. The dental stud-ent's attitude towards the profession as reflected in his oral cavity. Egypt Dent $J$ 1969;15:104-109.

8. Al Kawas S, Fakhruddin KS, Ur Rehman B. A comparative study of oral health attitudes and behaviour between dental and medical students; the impact of dental education in United Arab Emirates. J Int Dent Med Res 2010;3: 6-10.

9. Kawamura M, Yip HK, Hu DY, Komabayashi T. A cross-cultural comparison of dental health attitudes and behavior among freshman dental students in Japan, Hong-Kong and West China. Int Dent J 2001;51:159-163.

10. Fermin A Carranza. Glickman's Clinical Periodontology. W.B. Saunders Company. 1990:310.

11. Ainamo J, Bay I. Problems and proposals for recording gingivitis and plaque. Int Dent $J$ 1975;25:229-235.

12. Al-Omari QD, Hamasha AA. Gender-Specific Oral Health Attitudes and Behavior among Dental Students in Jordan. $J$ Contemp Dent Pract 2005;6:107-114.

13. Al-Wahadni A M, AL-Omiri M K, Kawamura M .Differences in self-reported oral health behavior between dental students and dental technology/dental hygiene students in Jordan. J Oral Sci 2004;46:191-197.

14. Petersen PE, Peng B, Tai B, Bian Z, Fan M. Effect of a school-based oral health education programme in Wuhan City, Peoples' Republic of China. Int Dent J 2004;54:33-41.

15. Kawamura M, Honkala E, Widström E, Komabayashi T. Cross-cultural differences of self-reported oral health behaviour in Japanese and Finnish dental students. Int Dent $J$ 2000;50:46-50.

16. Khami MR, Virtanem JI, Jafarian M, Murtomaa H. Prevention-oriented practice of Iranian senior dental students. Eur J Dental Educ 2007;11:48-53.

17. Neeraja R, Kayalvizhi G, Sangeeta P. Oral health attitudes and behaviour among a group of dental students in Bangalore, India. Eur J Dent 2011;5:163-167.

18. Bakdash M B, Proshek JM. Oral hygiene status of dental students as related to their personal and academic profiles. J Periodontal Res1979;14:438-443. 